\title{
Supply chain resilience and operational performance amid COVID-19 supply chain interruptions: Evidence from South Korean manufacturers
}

\author{
Minhyo Kang ${ }^{\mathrm{a}}$ and Aaron Rae Stephens ${ }^{\mathrm{b}^{*}}$
}

${ }^{a}$ Busan University of Foreign Studies, South Korea ${ }^{b}$ Hartwick College, United States

\section{A B S T R A C T}

\begin{tabular}{l} 
Article history: \\
Received October 18, 2021 \\
Received in revised format \\
October 30,2021 \\
Accepted December 302021 \\
Available online \\
December 302021 \\
\hline Keywords: \\
Supply chain disruption \\
orientation \\
Supply chain resilience \\
Digital infrastructure capability \\
PLS-SEM \\
Innovation
\end{tabular}

Article history:

Received October 18, 2021

eeived in revised format

Accepted December 302021

Available online

Keywords:

Supply chain disruption

Supply chain resilience

PLS-SEM

Innovation

\begin{abstract}
South Korean manufacturers have dealt with supply chain interruptions from the COVID-19 pandemic as many other manufacturers have around the world; however, it seems that some Korean manufacturers are remarkably resilient. Many Korean manufacturers have withstood perilous supply chain dynamism and maintained operational performance without interruption. This study examines the antecedents of supply chain resilience and operational performance to suggest how other manufacturers can develop and maintain continuous uninterrupted operations even amid dynamic supply chains and global disruption. This is an empirical study of South Korean manufacturers utilizing PLS-SEM analysis with mediation effects. This study examines the interrelationships of six variables including, supply chain disruption orientation, management's intention, digital infrastructure capability, innovation adoption, supply chain resilience, and operational performance. The implications are meaningful for both scholars and practitioners alike. This paper contributes to literature pertaining to both supply chain management and technology assimilation.
\end{abstract}

(C) 2022 Growing Science Ltd. All rights reserved.

\section{Introduction}

Global volatility and uncertainty surrounding the COVID-19 pandemic and significant disruptions within supply chains have led to devastation for many companies dependent upon global supply chains (Goodman et al., 2021; Jee \& Bae, 2020; Bret, 2020). The pandemic has driven caution throughout the business world but especially among innovators and start-ups (Tashanova et al., 2020); moreover, innovative manufacturers (especially in Korea) have struggled to attract investors (Jee $\& \mathrm{Bae}, 2020)$. If this trend continues, Korean industry could be permanently stunted by lackluster investment in innovation (Jee \& Bae, 2020). Enthusiasm for start-ups and new technology were expected to drive South Korean manufacturers through the fourth industrial revolution. If innovation is stifled by investor restraint, it threatens Korea's dynamic economic future. Despite caution and concern among investors, there is still reason to believe that process innovation is driving supply chain resilience and operational performance even amid lackluster investment from investors; dynamic supply chains have been known to lead to improved supply chain resilience ( $\mathrm{Yu}$ et al., 2019). In this case, the most dynamic innovation may not be out in front but hidden within manufacturing. It is conceivable that Korean innovation and dynamo has not stopped but is continuing to drive supply chain resilience and operational performance especially amid the current crisis. Economic uncertainty concerning international politics and trade bloc disputes even before COVID-19 had already inflamed supply chains; supply chain managers were likely already overwhelmed and weary of the tumultuous international arena (Melnyk, 2014). Trade liberalization had lately been side-lined for many nations in return for protectionism and nationalism, e.g. BREXIT and Trump era trade policies. Rising political risks may have already primed many supply chain managers for the prospect of additional supply chain interruptions caused by COVID-19; thus, making it easier for companies to rapidly adapt to such disruptions. 
Vulnerabilities due to supply chain interdependence and interconnectedness have been highlighted (Manners-Bell, 2020; Sawik, 2020); for example, fires and floods have led to factory slowdowns, closures and interruptions (Sheffi, 2005; Singh \& Singh, 2019); moreover, such disruptions are expected to become more frequent as global climate change is likely to fuel more natural disasters (Bret, 2020). How companies rapidly develop supply chain resilience and operational excellence even amid such dynamism will be of ever increasing value. Rapid globalization of supply chains has led to increased exposure to supply chain risks that remain faintly fathomed by practitioners; moreover, without accounting for such risks and proper preparation, supply chain collapse remains an eminent possibility for many companies (Sawik, 2020; Ponis, 2010; Sheffi, 2005). Firms must recognize how they can adapt amid ever more dynamic and disruptive environments. Considering extraordinary uncertainty and the consequential risks, many companies try to avoid unforeseen threats; they utilize principles of supply chain management to optimize efficiency and minimize risk (Chandra \& Grabius, 2007). Although global supply chains may seem rigid and static, rapid fluctuations in politics, climate and unforeseen risks do emerge and upend supply chains without much warning (Polyviou et al., 2020; Melnyk, et al., 2014). Although the possibility of a pandemic seems remote, they are in fact quite inevitable; furthermore, it is likely that we will see more pandemics because of climate change and globalization (Pike et al., 2014). Thus, many companies stand at a critical point where they must provision themselves for such risks amid great uncertainty (Polyviou et al., 2020; Scheer et al., 2006). With the mantra of extraordinary uncertainty in hand, practitioners are now more eager than ever to know how to build supply chain resilience and maintain regular operations even amid great dynamism. Supply chain resilience stands out among extant literature as a critical solution for maintaining operational performance despite supply chain dynamism (Yu et al., 2019; Melnyk et al., 2014); nevertheless; it is unclear what develops supply chain resilience; furthermore, the interrelationships are unclear with other variables including management, organizational culture, technology, and innovation. This research seeks to explore and confirm the interrelationships that build supply chain resilience and improve operational performance even amid COVID-19 supply chain turmoil; thus, several key questions arise: 1 . how can practitioners maintain operational performance amid dynamic supply chains, 2. what is critical to successfully developing supply chain resilience? 3. What areas should a firm focus on for generating supply chain resilience and operational performance especially amid COVID-19? These research questions are answered within this manuscript through an empirical study of South Korean manufactures responding to COVID-19 supply chain interruptions.

Following this introduction, a literature review is detailed in the following section. The literature review examines previous research in order to propose hypotheses and build a conceptual framework. Psychosomatic variables are extracted from extant literature within the methodology section. First the outer model is tested for reliability and validity then the inner model is tested all utilizing Smart PLS 3.0. The results indicate key variables (supply chain disruption orientation, management's intention, digital technology capability, and innovation adoption) build supply chain resilience and operational performance (performance). Implications are detailed for both practitioners and scholars in the discussion. Finally, a conclusion considers contributions, limitations and future research.

\section{Literature review}

\subsection{COVID-19 and supply chain resilience}

As an airborne virus COVID-19 quickly spread around the world. By March of 2020 many industrialized nations had decided to slow the spread of the virus through lockdowns, temporarily halting unnecessary activities. Such lockdowns were globally adopted after early successes in Asia. Media and logistics researchers quickly realized that such lockdowns were not only impacting local economies but also countries not under lockdown. This was evident in South Korean manufacturing. According to the Hankook Newspaper website, as of August 23 2020, Samsung Electronics was forced to halt production several times during the first half of 2020 even before any lockdowns in South Korea because of interruptions in the supply chain. Additionally, based on the website run by the Korea International Trade Association (KITA), Hyundai and Kia both dealt with several shutdowns despite South Korea not being under lockdown for much of 2020. Supply chain interruptions in South Korea are evidenced by the major Chaebols shutting down production because of unavailable supplies. Globally, this phenomenon related to COVID-19 was examined through the lens of supply chain resilience; indeed, interest in this topic area rapidly expanded, seemingly overnight (Belhadi et al., 2021; Gu et al., 2021; Ali et al., 2021; Baz \& Ruel, 2021).

\subsection{Supply chain interruption and risk management}

Several theories have arisen from risk management regarding the management of interruptions including, normal accident theory and the Swiss cheese model among others (Perrow, 1994; Reason, 1977). According to normal accident theory, accidents are expected; moreover, they become more frequent as systems become more complex and the dependence upon coupling of components increases (Sagan, 1995; Perrow, 1994; Chopra \& Meindl, 2010). Larger systems with more interactions inevitably produce more opportunities for failure (Sagan, 1995). The extraordinary complexity of global supply chains naturally increases the number of opportunities for failures. As production systems have become increasingly more complex with artificial intelligence, robotics and other technologies, it is also expected that opportunities for failure will increase within operations. Based upon the increasing inevitability of accidents and interruptions, it is well understood that firms will continue to encounter such incidents. 
The Swiss cheese model focuses on layers of defense against failures (Reason, 1977). In this regard, several opportunities to catch mistakes or failures exist within a system; additionally, more layers provide better protection from a failure occurring. Layers of defense have been differentiated as either soft defenses (people and management) or hard defenses (infrastructure and technology) (Hosseinian \& Torghabeh, 2012; Reason, 1977). It is up to firms to produce an appropriate combination of soft and hard defenses in order to catch all variances before they become failures. Supply chain interruptions are notably more frequent as COVID-19 has generated havoc in global supply chains. Such interruptions negatively impact operational performance (Chen et al., 2015; Wagner and Bode 2008). Nevertheless, innovation, more specifically, the magnitude of that innovation, has in the past, proven to mitigate the degradation of such supply chain interruptions (Golgeci \& Pnomarov, 2013). Moreover, manufacturing firms have benefited by building supply chain resilience, especially amid dynamic supply chains (Ali et al., 2017; Sheffi \& Rice, 2005). This area of research is known as supply chain risk management (Jüttner et al., 2003; Jüttner \& Maklan, 2011). Research to date has included the dynamic capabilities framework and the strategic orientations framework to frame how organizations adapt to such turbulence (Yu et al., 2019; Gu \& Huo, 2017, 2021; Blome et al., 2013).

\subsection{Theoretical underpinning: resource-based view}

Researchers examining supply chain resilience have frequently viewed this research through the lens of the resource-based view and dynamic capabilities (Baz \& Ruel, 2021; Brusset \& Teller; 2017; Chowdhury \& Quaddus, 2017); thus, it is appropriate to frame this empirical model utilizing the resource-based view. According to Barney (1991), firms are bundles of resources that include physical capital (e.g., technological infrastructure), human capital (e.g. management), and organizational capital (e.g. organizational culture) among other resources; thus, the resource-based view mentioned by Barney (1991) establishes the theoretical framework that supports this model. Moreover, core SCM theories link the variables within the model including normal accident theory and the Swiss cheese model, while the resource-based view serves as the theoretical underpinning.

\subsection{Supply chain disruption orientation}

Much research has focused on how disruptions impact the supply chain and a firm's competitiveness amid such interruptions (Parast, 2020; Yu et al., 2019; Kamalahmadi \& Parast, 2016); indeed, this research is more critical today as interruptions have become the norm amid COVID-19. The term disruption has many meanings; however, in the context of supply chain disruption orientation, it refers to the ability of a firm to break apart fixed supply chains and operations in order to rapidly realign supply chains and operations amid frequent interruptions (Bode et al., 2011). Strategic orientations are utilized to understand how an organization's culture impacts its strategic decision-making and behavior (Ocasio, 1997). According to the attention-based view, organizations focus on an area of strategic importance (e.g., market for market orientation, technology for technology orientation, or innovation for innovation orientation) that guides the organization in decisionmaking. In the case of supply chain disruption orientation, the firm is focused on reducing the impacts of interruptions within the firm's supply chain, and how to deal with the next set of interruptions (Bode et al., 2011). The original notion of supply chain disruption orientation first described by Bode et al., (2011) emphasized information processing and the amalgamation of resources. Subsequent research also emphasized information processing and resource mixing (Yu et al., 2021; Jihadi et al., 2020); thus, supply chain disruption orientation implies an organizational culture that contributes to both enhanced information processing and resource merging. Supply chain disruption orientation is a competitive strategy for firms that operate within particularly dynamic supply chains (Ambulkar et al., 2015). Firms that have a supply chain disruption orientation are able to rapidly reconfigure (supply chains and operations) in order to develop supply chain resilience (Manners-Bell, 2020; Ambulkar et al., 2015; Bode et al., 2011). This type of behavior is characterized as proactive learning from experience (Ambulkar et al., 2011; Jermsittiparsert et al., 2019). Lately, supply chains are particularly dynamic as interruptions from the COVID-19 pandemic have impacted nearly all areas of operational importance globally. It is therefore reasonable to suspect that many Korean manufacturers have adopted some level of supply chain disruption orientation in order to remain competitive amid increased dynamism. This would explain continued competitiveness of manufactures even amid extraordinary supply chain interruptions.

Organizational culture likely plays a significant role in the adoption of innovation as well as the development of supply chain resilience. Firms that are continuously challenged by dynamic supply chains require constant attention to such developments in order to rapidly adapt (Mubarik et al., 2021). Research regarding Malaysian firms by Mubarik et al., (2021) found that firms with greater supply chain visibility through digital mapping were able to develop supply chain resilience; moreover, they felt hard defenses such as technology and soft defenses such as people both contributed to supply chain resilience. Previous studies emphasize the benefits of supply chain disruption orientation (Jihadi et al., 2020; Yu et al., 2019; Bode et al., 2011). While studying 455 manufacturers in Germany, Austria, and Switzerland Bode et al., (2011) found that supply chain disruption orientation bolstered both buffering and bridging of supply chains. Additionally, a study of 345 Indonesian manufacturers exhibiting supply chain disruption orientation also maintained better supply chain resilience (Jihadi et al., 2020). A study of 241 Chinese manufacturers by Yu et al., (2019) found that supply chain disruption orientation led firms to supply chain resilience, especially amid dynamic supply chains; firms practicing in especially turbulent supply chains were more likely to exhibit characteristics of supply chain disruption orientation. All three studies suggested that supply chain 
disruption orientation enhanced information processing and resource mixing. Firms that develop supply chain visibility through appropriate innovation adoption and organizational culture likely develop more supply chain resilience; thus, the first two hypotheses are proposed:

Hypothesis 1: Supply chain disruption orientation supports innovation adoption.

Hypothesis 2: Supply chain disruption orientation improves supply chain resilience.

\subsection{Innovation adoption}

The adoption of innovation is widely studied in the context of the organizations and at the individual-level (mostly as consumer research). Organizational research focuses on three key models for the adoption and diffusion of technology: institutional theory (INT) (DiMaggio \& Powell 1983); technology-organization-environment (TOE) framework (Tornatzky \& Fleischer, 1990); and the diffusion of innovation (DoI) theory (Rogers, 2003). Consumer/individual-level research (relevant here because managers are individuals that frequently make decisions at the personal level especially in smaller organizations) has emphasized three models: technology acceptance model (TAM) (Davis, 1989); the theory of planned behavior (TPB) (Ajzen, 1991); and the unified theory of acceptance and use of technology (UTAUT) (Venkatesh et al., 2003). Each theory exhibits advantages and disadvantages respectfully; however, all are widely used. Organizational adoption of innovation is well studied; however, the impacts of management's intention and adoption of innovation is less well studied. Nevertheless, the individual intentions of management likely play a critical role in the adoption of innovation. Intention to use/adopt is widely studied in IT, mobile commerce and e-commerce literature through the unified theory of acceptance and use of technology model outlined by Venkatesh, et al., (2003); accordingly, an individual is driven by antecedents (attitudes, values etc.) to an intention to use new technology; intention to use is a distinct step. Finally, the individual decides (sometimes they decide to use it and sometimes they do not). The model is popular because it provides a framework for adding an infinite number of reasons why an individual may choose to utilize a new technology or not. It also highlights the gap between intention (a cognitive process) and behavior (action). In business there is also a gap between intention and action; in this case, it should be emphasized; when management's desires are not met, it is likely there are detrimental effects. Management, in particular, supply chain managers, are experienced and well-trained professionals. What happens when the organization does not listen to management's advice?

Although UTAUT is principally employed to characterize consumer behavior, it has been adopted to emphasize the gap between management-level intention to use and the organization's adoption of new technology; it is especially useful when focusing on the gap between management's wishes and the organization's ultimate decision. Some studies have adopted such a framework; for example, while focusing on green IT in Malaysian manufacturing, Asadi et al. (2019) created an extensive model explaining why some firms intend to adopt green technology. Another study by Liu et al., (2010) utilized the UTAUT model to understand the organizational adoption of internet-enabled supply chain management systems in Chinese firms. Indeed, the model seems useful when studying manager intention and action. As previous studies illustrate, supply chain managers are individuals with intentions that do not always get realized within the organization; given the uncertainty of action versus intention between manager and organizational behavior, it is especially meaningful to explore this relationship. Supply chain managers are the decision-makers that guide the firm through operational and supply chain interruptions; furthermore, management's role is central to the innovative process (Manners-Bell, 2020; Mentzer et al., 2001). When management is behind innovation it is more wholly adopted and integrated into the firm (Melnyk, 2014; Cooper et al., 1997; Mentzer et al., 2001); otherwise, it likely deteriorates and can be lost. Management must lead organizations through tough times with good decision-making and charisma. Without management, a firm is aimless; moreover, management's role is critical to both the acceptance of innovation and the development of supply chain resilience. Organizations require managers to lead them in innovation adoption and supply chain management (Mubarik et al., 2021). Supply chain resilience is enhanced by manager engagement in the innovation adoption process; only managers know the critical metrics within their supply chains that must be visible in order to adapt to interruptions on time (Mubarik et al., 2021). When managers are not involved in the innovation development process, it is more likely that critical metrics (necessary supply chain mapping and visibility are not achieved) will not be provided; thus supply chain resilience will not be developed. However, when management is engaged in the adoption process, they make sure critical points of supply chain visibility are met; supply chain mapping and visibility through innovation is enriched. Furthermore, supply chain resilience can be established with better technology. It is likely that management's intention leads to both the adoption of critical innovations and more importantly, the formation of supply chain resilience.

According to Gu et al. (2021) supply chain managers implement supply chain IT for explorative and exploitative; implicitly supply chain managers decide whether the system will be exploitative or exploitive; moreover, supply chain managers utilize such systems from the supply side or from the customer side. Additionally, it is the role of the manager to determine the most effective method for implementing IT (Gu et al., 2021). Ultimately such IT was found to benefit both the supply side and customer side of the focal firm through developing resilience on both sides (Gu et al., 2021). Thus, two additional hypotheses are proposed:

Hypothesis 3: Management's intention improves innovation adoption. 
Hypothesis 4: Management's intention helps to form supply chain resilience. 2.6 Organizational learning

Another driver of innovation and change within a firm is its existing technological infrastructure, its technological capability (Singh \& Singh, 2019). Digital infrastructure is known to guide organizations through innovation adoption and help firms to develop supply chain resilience (Parast, 2020; Singh \& Singh, 2019; Golgeci \& Ponomarov, 2013). Firms already using digital technology likely grasp more readily how additional technology can improve operations; furthermore, it can be reasoned that such firms are more able to adopt technology as they have done so in the past. Existing technology, in this case, digital infrastructure capability, can be understood as a facilitator for organizational learning (Singh \& Singh, 2019). Organizational learning is considered a complex process facilitated by many factors. Drawing upon Argyris and Schön (1974), learning can be understood as having either a single loop (Model I) or a double loop (Model II). A single loop implies that the organization rapidly modifies without integrating organizational changes (Argyris and Schön, 1974); in other words, the firm does not change the paradigm or accept new disruptive change/innovation. The double loop suggests that the firm internalized and modified itself fundamentally in order to avoid future problems (Argyris \& Schön, 1974); double loop learning is deeper and more integrated (Stead \& Smallman, 1999). A firm that exhibits double loop learning likely adopted innovation in order to avoid future interruptions. A firm that utilizes the single loop approach likely only has minor adjustments that temporarily fix the problem. Double loop organizational learning is indicative of disruptive organizational change indicated in supply chain disruption orientation; moreover, innovation adoption is likely. If double loop organizational learning has occurred it is likely to form supply chain resilience and improve operational performance. Both supply chain mapping and visibility were found to be significant factors for improving supply chain resilience in electronic sector firms in Malaysia (Mubarik et al., 2021). Mapping (process mapping, upstream mapping and downstream mapping) and visibility (demand visibility, supply visibility and market visibility) all improved the ability of firms to develop resilience (SC alertness, SC agility and SC preparedness) to interruptions (Mubarik et al., (2021). When a firm can see disruptions before they hit operations, the firm can rapidly reconfigure to avoid shut downs. Visibility allows the firm to be alert. Mapping allows the firm to rapidly reconfigure supplies in order to avoid operational shutdowns. All of this, is facilitated through digital infrastructure capability, the ability of the firm to use technology for supply chain management. It is likely digital infrastructure capability is a key facilitator for developing supply chain resilience. Digital infrastructure capability likely facilitates double-loop learning through the development of supply chain mapping, visibility, and resilience. The most appropriate and necessary innovations are adopted forming supply chain resilience and preserving operational performance; thus, several additional hypotheses are proposed:

Hypothesis 5: Digital infrastructure capability increases innovation adoption. Hypothesis 6: Digital infrastructure capability improves to supply chain resilience.

\subsection{Organizational information processing theory}

Organizational information processing theory (OIPT) as described by Galbraith, (1973) and (1974) has served as the theoretical underpinning for those studying supply chain resilience and information management (Gu et al., 2021; Wong et al., 2020). Firms that develop a robust information processing capability are better able to navigate tumultuous business environments (Galbraith, 1973). Additionally, firms operate within an open environment with open information processing systems implying that information can be processed and used to avoid calamities as they approach (Galbraith, 1974). Appropriate innovation adoption improves information processing that leads to both better supply chain resilience and operational performance amid dynamism. Gu et al. (2021) found that the appropriate adoption of IT was particularly beneficial for creating supply chain resilience and performance while studying 206 Chinese manufacturers amid COVID-19. Additionally, Wong et al. (2021) while studying 236 Taiwanese firms theorized that information processing was the basis for understanding how IT drives supply chain resilience and operational performance. Organizational information processing theory and evidence from Taiwan and China suggest that the appropriate use of information management can improve supply chain resilience and operational performance; thus, two more hypotheses are proposed.

Hypothesis 7: Innovation adoption improves operational performance. Hypothesis 8: Innovation adoption improves supply chain resilience.

\subsection{Supply chain resilience and operational performance}

Studies have found that supply chain resilience improves many measures of organizational performance (Yu et al., 2019; Wong et al., 2020). Yu et al. (2019) surveyed 241 Chinese firms and found that supply chain resilience led to better financial performance; more specifically, supply chain disruption orientation developed supply chain resilience which led to improved financial performance. Following a line of reasoning, supply chain resilience likely resulted in fewer interruptions of operations; thus, fewer interruptions of customer deliveries and fewer issues with cash flows. When operations are steadily maintained, a firm can deliver on-time to customers without added expenses caused by interruptions. Another study of 236 Chinese firms by Wong et al., (2020) found supply chain resilience benefits risk management, financial performance and market performance. Once more, there is a link to improved measures of firm performance; however, operational 
performance is notably absent from the literature. Although it may seem obvious that operations would be improved with supply chain resilience, it remains untested. Research must examine all linkages between resilience and performance; thus, another hypothesis is proposed:

Hypothesis 9: Supply chain resilience improves operational performance.

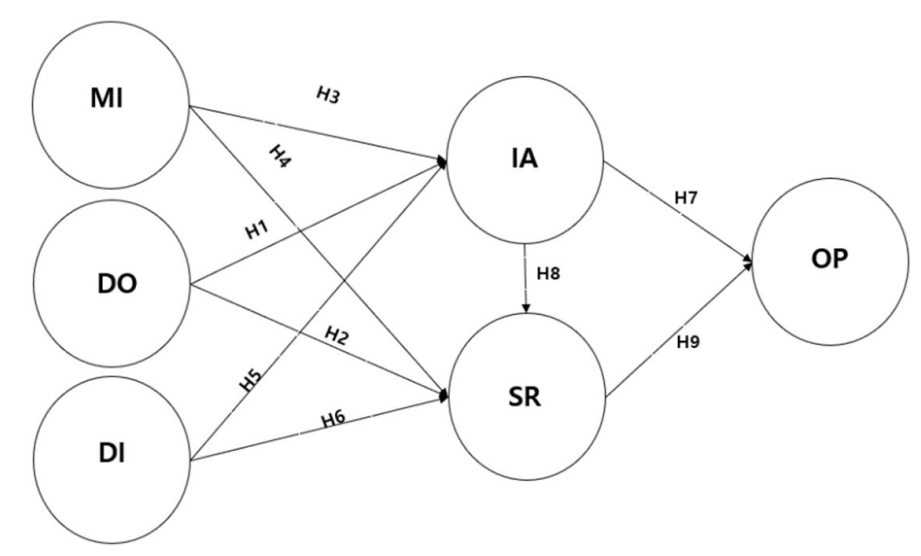

Fig. 1. The proposed study

\subsection{Mediation effects}

Mediation effects are suspected for both innovation adoption and supply chain resilience. Mediation suggests that the effects of the independent variables are amplified by the mediating variable. It is suspected that innovation adoption mediates the relationships between the independent variables (management intention, supply chain disruption orientation and digital infrastructure capability) as innovation adoption represents concrete change in operations; moreover, when innovations are adopted, they likely have positive impacts upon operations that result in improved operational performance. Supply chain resilience also likely mediates the relationships between the independent variables and operational performance. In both cases (innovation adoption and supply chain resilience), mediation effects indicate double loop organizational learning. Supply chain resilience is a strong indicator of positive change in managing interruptions within the supply chain; moreover, it shows the problem was addressed through a paradigm change, indicative of double loop learning. The two variables (innovation adoption and supply chain resilience) are both expected to facilitate operational performance; therefore, it is also likely that they mediate the relationships between the independent variables and operational performance. Mediating variables imply strong and meaningful relationships between the variables of the model. Confirming the mediation effects also enhances the model. Innovation adoption and supply chain resilience likely mediate the relationships between supply chain disruption orientation and operational performance. Organizational culture alone should not contribute to improved operational performance; it must enable something that in-turn leads to operational performance. When organizational culture leads to innovation adoption or supply chain resilience, it leads to improved operational performance. Thus, two additional hypotheses are proposed:

Hypothesis 10: Innovation adoption mediates the relationship between supply chain disruption orientation and operational performance.

Hypothesis 11: Supply chain resilience mediates the relationship between supply chain disruption orientation and operational performance.

Management's intention should only result in improved operational performance if innovations are appropriately adopted; furthermore, when innovation adoption is well managed it should result in better operational performance. It is suspected that innovation adoption mediates the relationship between management intention and operational performance; thus, reflecting this relationship. Additionally, it is possible that supply chain resilience mediates the relationship between management's intention and operational performance. Again, unless management's intention enables something concrete, it is unlikely it'll improve operational performance alone. Additionally, two more hypotheses are proposed:

Hypothesis 12: Innovation adoption mediates the relationship between management's intention and operational performance.

Hypothesis 13: Supply chain resilience mediates the relationship between management's intention and operational performance. 
It is further suspected that innovation adoption and supply chain resilience mediate the relationship between digital infrastructure capability and operational performance. It is unlikely digital infrastructure capability alone leads to improved operational performance. When digital infrastructure capability leads to tangible changes (innovation adoption and supply chain resilience) it makes sense that operational performance would be improved. Innovation adoption can imply that double loop learning and it should indicate operational performance. Supply chain resilience implies an improvement in supply chain management; that too should lead to better operational performance. The absence of innovation adoption and supply chain resilience likely obscure the impacts of digital infrastructure capability upon operational performance; thus, two additional hypotheses are proposed:

Hypothesis 14: Innovation adoption mediates the relationship between digital infrastructure capability and operational performance.

Hypothesis 15: Supply chain resilience mediates the relationship between digital infrastructure capability and operational performance.

Finally, it is suspected that supply chain resilience mediates the relationship between innovation adoption and operational performance. Unless an adopted innovation leads to a concrete improvement, i.e., supply chain resilience, it may not necessarily lead to better operational performance. Amid COVID-19 and continuous supply chain dynamism, it is likely more vital that innovations do lead to supply chain resilience. Without improved supply chain resilience amid continuous interruption, it is unlikely adoptions improve operational performance much. Therefore, the final hypothesis is proposed:

Hypothesis 16: Supply chain resilience mediates the relationship between innovation adoption and operational performance.

\section{Methodology}

\subsection{Sample}

A survey was sent out via email to 200 South Korean manufacturing firms over a 2 month period ending in December of 2020. A stratified sampling method was used to select 200 Korean manufacturers from a Korean Chamber of Commerce list. Less incomplete or improper returned surveys, 76 complete responses were retained for our study. Over 90\% (70) of the respondents had a position in the company that was above the management level (at the director or executive level). Considering turnover, 60 companies had a turnover less than 50 billion KRW annually. Many of the companies (50) were within the automobile industry and 10 were associated with the electronics industry. Additionally, 16 companies were associated with other industries, i.e. ship building or heavy industry. More than $95 \%$ of the companies had some sort of digital supply chain management in operation for more than a year used to manage marketing, logistics or purchasing.

\subsection{Operationalization of variables}

There are six psychosomatic variables operationalized for this research from extant literature including, supply chain disruption orientation, management's intention, digital infrastructure capability, innovation adoption, supply chain resilience and operational performance. The variables were measured on a 5-point Likert scale. To assist with data collection in Korea the items (questions) were adopted from previous literature then translated into Korean and back-translated for accuracy. The back-translated questions are viewable in Table 1 with references referring to their origins. Management's intention refers to management's intention to adopt innovation (Han \& Hyun, 2017; Akman \& Mishra, 2014). Many variations exist to measure management's intention with regard to many types of innovation including green innovation (Asadi et al., 2019) and management's intention to adopt robots (Simões et al., 2020). In this case, it is adapted to focus on digital innovations for supply chain management. Supply chain disruption orientation was operationalized by Bode et al., (2011); moreover, they used it to study how firms implemented better coping mechanisms for future disruptions. It has since been used in a multitude of other studies as a means for understanding how supply chain resilience is developed through organizational culture (Ambulkar et al., 2015; Blackhurst et al., 2011; Scholten \& Schilder, 2015; Stevenson \& Busby, 2015; Yu et al., 2019). Supply chain disruption orientation is further adapted for the specific context of this study, the adoption of digital innovation and supply chain resilience amid COVID-19 interruptions. Digital infrastructure capability was modified from a variable (infrastructure capabilities) employed by Singh and Singh, (2019); the adapted variable represents digital supply chain management infrastructure. Puviyarasu and Cunha (2021) indicate that in order for digital infrastructure to be highly advanced it should influence value driven factors that may include more efficient stock management, increased transparency or the optimization of smart factory production. Digital infrastructure capability within an organization enables the firm to appraise the impacts of risks upon supply chains and develop contingencies (Tan et al., 2015). Digital infrastructure capability can also be summarized as a firm's capability to effectively use digital infrastructure for supply chain management. The construct operational outcome was adopted from Kaplan and Norton, (1996); accordingly it measures the performance of operations over the past three years. In the case of this research three measures are found to be important: delivery performance, stock and shutdowns are considered. Flynn et al. (2010) measured on-time delivery and quick response to 
market changes as operational performance. Furthermore, Kang and Kim (2017) also included delivery performance and stock management as a measure for operational performance. Supply chain resilience, a newer construct, was operationalized and used in three recent studies (Golgeci \& Ponomarov, 2013; Wong et al., 2020; Yu et al., 2019). A multitude of other studies have adopted supply chain resilience in various contexts (Mubarik et al., 2021; Yu et al., 2019; Wong et al., 2020). Wong et al. (2020) used the construct to study information processing and its impacts on supply chain resilience. Yu et al., (2019) adopted the construct as a dynamic capability to study the impacts of dynamic supply chains. Finally, it was adopted by Mubarik et al., (2021) to understand the impacts of supply chain mapping and visualization. The construct is valuable as a means of measuring supply chain resilience in many contexts; thus, it is adopted in this research.

Table 1

Operationalisation of the Research Instrument

\begin{tabular}{|c|c|c|c|}
\hline Variable & $\begin{array}{l}\text { Operational } \\
\text { definition }\end{array}$ & Measurement items & Prior research \\
\hline \multirow{3}{*}{$\begin{array}{l}\text { Management's } \\
\text { Intention }\end{array}$} & \multirow{3}{*}{$\begin{array}{l}\text { The degree to which } \\
\text { management follows } \\
\text { and supports the } \\
\text { adoption of new } \\
\text { technology. }\end{array}$} & $\begin{array}{l}\text { [MI1] There is a process for rapidly resolving supply chain disruptions } \\
\text { especially with new technology. }\end{array}$ & \multirow{3}{*}{$\begin{array}{l}\text { Venkatesh et al., } \\
\text { 2003; Han and } \\
\text { Hyun, 2017; } \\
\text { Akman and } \\
\text { Mishra; 2014 }\end{array}$} \\
\hline & & $\begin{array}{l}\text { [MI2] Managers are continuously considering the latest innovative } \\
\text { technology. }\end{array}$ & \\
\hline & & $\begin{array}{l}\text { [MI3] Immediate action is expected by top management with regard to } \\
\text { resolving disruptions with new technology. }\end{array}$ & \\
\hline \multirow{3}{*}{$\begin{array}{l}\text { Supply Chain } \\
\text { Disruption } \\
\text { Orientation }\end{array}$} & \multirow{3}{*}{$\begin{array}{l}\text { The degree to which the } \\
\text { organizational culture is } \\
\text { focused on and prepared } \\
\text { for supply chain } \\
\text { disruptions. }\end{array}$} & $\begin{array}{l}\text { DO1] Everyone from management to employees are focused on } \\
\text { disruptions and prepared for immediate fixes. }\end{array}$ & \multirow{3}{*}{$\begin{array}{l}\text { Bode et al., 2011; } \\
\text { Yu et al., } 2019\end{array}$} \\
\hline & & $\begin{array}{l}\text { DO2] The organisation try to set up and keep the timeline, in order to } \\
\text { solve the disruption in supply chain. }\end{array}$ & \\
\hline & & $\begin{array}{l}\text { DO3 The effective communication with customer is implemented by } \\
\text { utilising a core competence, in order to solve the disruption among supply } \\
\text { chains. }\end{array}$ & \\
\hline \multirow{3}{*}{$\begin{array}{l}\text { Digital } \\
\text { Infrastructure } \\
\text { Capability }\end{array}$} & \multirow{3}{*}{$\begin{array}{l}\text { The degree to which the } \\
\text { firm relies on digital } \\
\text { technology for supply } \\
\text { chain management. }\end{array}$} & $\begin{array}{l}\text { [DI1] The company operates SCM utilising digital technology such as } \\
\text { ERP, AI or big data analytics. }\end{array}$ & \multirow{3}{*}{$\begin{array}{l}\text { Singh \& Singh, } \\
\qquad(2019)\end{array}$} \\
\hline & & $\begin{array}{l}\text { [DI2〕 Supply chain managers can review stock utilising digital } \\
\text { technology. }\end{array}$ & \\
\hline & & $\begin{array}{l}\text { [DI3] Utilising digital technology managers are able to check the } \\
\text { production volume daily/weekly/monthly. }\end{array}$ & \\
\hline \multirow{3}{*}{$\begin{array}{l}\text { Innovation } \\
\text { Adoption }\end{array}$} & \multirow{3}{*}{$\begin{array}{l}\text { The degree to which the } \\
\text { firm adopts innovation } \\
\text { as a solution to supply } \\
\text { chain management } \\
\text { issues. }\end{array}$} & $\begin{array}{l}\text { [IA1] Within the company, it is easy to both discuss and get approved new } \\
\text { technology for supply chain management. }\end{array}$ & \multirow{3}{*}{$\begin{array}{l}\text { Venkatesh et al., } \\
2003\end{array}$} \\
\hline & & $\begin{array}{l}\text { [IA2〕 There is a common understanding between management and } \\
\text { employees that new technology will result in better performance. }\end{array}$ & \\
\hline & & $\begin{array}{l}\text { [IA3] This company actively seeks new technology for supply chain } \\
\text { management }\end{array}$ & \\
\hline \multirow{3}{*}{$\begin{array}{l}\text { Operational } \\
\text { Performance }\end{array}$} & \multirow{3}{*}{$\begin{array}{l}\text { The operational } \\
\text { performance of the firm. }\end{array}$} & $\begin{array}{l}\text { [OP1] Our delivery performance has improved over the past three years } \\
\text { because of supply chain management. }\end{array}$ & \multirow{3}{*}{$\begin{array}{l}\text { Kaplan \& Norton, } \\
1996\end{array}$} \\
\hline & & $\begin{array}{l}\text { [OP2] Our stock has been appropriately managed over the past three years } \\
\text { due to supply chain management. }\end{array}$ & \\
\hline & & $\begin{array}{l}\text { [OP3] Supply chain management has helped our company to avoid a } \\
\text { shutdown in the past three years. }\end{array}$ & \\
\hline \multirow{3}{*}{$\begin{array}{l}\text { Supply Chain } \\
\text { Resilience }\end{array}$} & \multirow{3}{*}{$\begin{array}{l}\text { The ability to avoid } \\
\text { operational interruptions } \\
\text { due to supply chain } \\
\text { interruptions and/or } \\
\text { recover rapidly from } \\
\text { disruptions. }\end{array}$} & $\begin{array}{l}\text { [SR1] Through company agility, we are able to continue operations amid } \\
\text { supply chain interruptions. }\end{array}$ & \multirow{3}{*}{$\begin{array}{c}\text { Golgeci and } \\
\text { Ponomarov, 2013; } \\
\text { Wong et al., 2020; } \\
\text { Yu et al., } 2019\end{array}$} \\
\hline & & $\begin{array}{l}\text { [SR2] Exceptionally, this company is able to avoid operational shutdowns } \\
\text { due to supply chain interruptions. }\end{array}$ & \\
\hline & & $\begin{array}{l}\text { [SR3] When shutdowns or interruptions occur, this company quickly } \\
\text { recovers. }\end{array}$ & \\
\hline
\end{tabular}

\section{Data Analysis and Results}

\subsection{PLS-SEM}

Partial least squares structural equation modeling (PLS-SEM) is the ideal statistical analysis methodology for this dataset considering the sample size and proposed model. Literature has addressed the matter of smaller sample sizes and PLS-SEM, the consensus is that PLS-SEM is an ideal method for smaller sample sizes (Marcoulides \& Saunders, 2006; Ringle et al., 2012; Richter et al., 2016). Seventy-six samples for this structural model is more than sufficient based upon the rule of thumb proposed by Barclay et al. (1995); furthermore, that rule stipulates that sample sizes should be 10 times either the number of pathways directed from any variable within the inner model or 10 times the number of indicators for any latent construct on the outer model; moreover, the higher of either should be multiplied by 10 to indicate the minimum sample size (Barclay et al., 1995). The highest number indicated by this model is 3; thus, 30 samples (10 times the number of pathways or indicators) should produce robust results. With seventy-six samples, this sample size is more than double the necessary number required. Accordingly, PLS-SEM is utilized for analysis of the inner and outer model. 


\subsection{Outer model assessment}

When using PLS-SEM the outer model should be measured and confirmed before the inner model; it should be confirmed that the psychosomatic variables are measured by the items of the survey. Utilizing Smart PLS 3.0, several measurements were assessed to confirm the outer model. Statistics from that analysis can be reviewed in Table 2: Outer Model Assessment. Internal consistency reliability is confirmed with Cronbach's alpha and composite reliability (Hair et al., 2014); moreover, internal consistency is confirmed by composite reliability when values are above 0.7 (Hair et al., 2014). Accordingly, all values for this model are above that threshold. Company-level research generally is more flexible with regard to Cronbach's alpha; values above 0.6 are considered acceptable when studying companies (Nunnally \& Bernstein, 1994). All values for Cronbach's alpha exceed 0.6; thus internal consistency is confirmed. After confirming the reliability of the outer model, validity of the outer model is typically established using several measures of validity. Convergent validity is usually measured using average variance extracted (AVE). The threshold for approving convergent validity using AVE is 0.5. Since all values are above 0.5 , convergent validity is established. Discriminant validity can be established by comparing cross loadings and more stringently by the Fornell and Larcker Criterion (Henseler et al., 2009; Fornell \& Larcker, 1981). The Fornell and Larcker Criterion suggests that the AVE of any construct must be higher than the highest squared correlation of any other constructs (Fornell \& Larcker, 1981); accordingly, discriminant validity is established in Table 3: Fornell and Larcker Criterion. Although cross loadings are not necessary for further establishing discriminant validity, they are provided for and do further establish validity (Hair et al., 2014; Henseler et al., 2009; Henseler \& Sarstedt, 2013).

Table 2

Outer Model Assessment

\begin{tabular}{|c|c|c|c|c|c|}
\hline Variable & Factors & Standard load & $\begin{array}{c}\text { AVE } \\
(\mathrm{AVE}>0.5)\end{array}$ & $\begin{array}{c}\text { Construct } \\
\text { Reliability } \\
(\text { C.R }>0.7)\end{array}$ & $\begin{array}{c}\text { Cronbach's } \\
\text { Alpha } \\
(\alpha>0.6)\end{array}$ \\
\hline \multirow{3}{*}{$\begin{array}{l}\text { Management's } \\
\text { Intention }\end{array}$} & MI1 & 0.748 & \multirow{3}{*}{0.731} & \multirow{3}{*}{0.890} & \multirow{3}{*}{0.814} \\
\hline & MI2 & 0.943 & & & \\
\hline & MI3 & 0.861 & & & \\
\hline \multirow{3}{*}{ Disruption Orientation } & DO1 & 0.724 & \multirow{3}{*}{0.691} & \multirow{3}{*}{0.870} & \multirow{3}{*}{0.780} \\
\hline & $\mathrm{DO} 2$ & 0.899 & & & \\
\hline & DO3 & 0.862 & & & \\
\hline Digital & DI1 & 0.734 & \multirow{3}{*}{0.629} & \multirow{3}{*}{0.834} & \multirow{3}{*}{0.695} \\
\hline \multirow{2}{*}{$\begin{array}{c}\text { Infrastructure } \\
\text { Capability }\end{array}$} & DI2 & 0.918 & & & \\
\hline & DI3 & 0.711 & & & \\
\hline \multirow{3}{*}{ Innovation Adoption } & IA1 & 0.892 & \multirow{3}{*}{0.769} & \multirow{3}{*}{0.909} & \multirow{3}{*}{0.848} \\
\hline & IA 2 & 0.937 & & & \\
\hline & IA3 & 0.797 & & & \\
\hline \multirow{3}{*}{ Supply Chain Resilience } & SR1 & 0.860 & \multirow{3}{*}{0.688} & \multirow{3}{*}{0.868} & \multirow{3}{*}{0.771} \\
\hline & SR2 & 0.881 & & & \\
\hline & SR3 & 0.740 & & & \\
\hline \multirow{3}{*}{$\begin{array}{l}\text { Operational } \\
\text { Performance }\end{array}$} & OP1 & 0.870 & \multirow{3}{*}{0.622} & \multirow{3}{*}{0.831} & \multirow{3}{*}{0.694} \\
\hline & OP2 & 0.755 & & & \\
\hline & OP3 & 0.735 & & & \\
\hline
\end{tabular}

Table 3

Fornell-Larcker Criterion

\begin{tabular}{c|ccccc}
\hline \multicolumn{2}{|c}{ IA } & DI & MI & DO & \\
\hline IA & $\mathbf{0 . 7 6 9}$ & & & & \\
DI & 0.225 & $\mathbf{0 . 6 2 9}$ & $\mathbf{0 . 7 3 1}$ & $\mathbf{0 . 6 9 1}$ & \\
MI & 0.212 & 0.086 & 0.210 & 0.445 & $\mathbf{0 . 6 2 2}$ \\
DO & 0.288 & 0.403 & 0.189 & 0.506 & 0.585 \\
OP & 0.473 & 0.393 & 0.181 & $\mathbf{0 . 6 8 8}$ \\
\hline SR & 0.348 & 0.406 &
\end{tabular}

IA: Innovation Adoption; SR: Supply Chain Resilience; DI: Digital Infrastructure Capability; MI: Management's Intention; DO: Supply Chain Disruption Orientation; OP: Operational Performance.

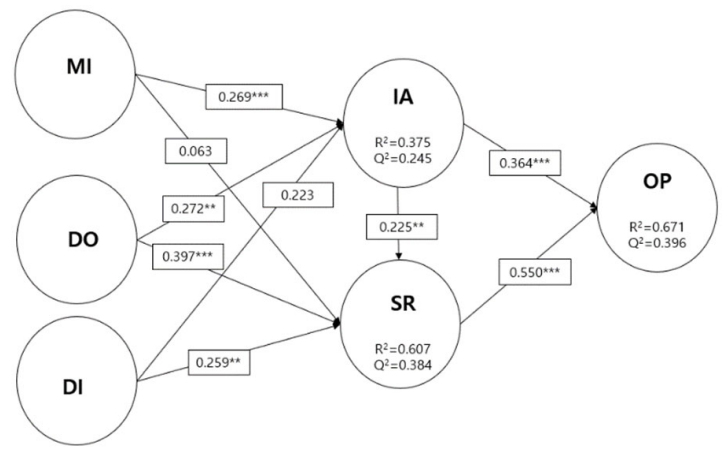

Fig. 2. The results of testing the hypotheses 


\subsection{Inner model assessment}

The inner model can be assessed once the outer model is established. Pathway coefficients are examined alongside significance scores, which in this case were obtained through bootstrapping to 600 samples with Smart PLS 3.0. Pathways that are found insignificant (p-values above 0.05 or pathway coefficients less than 0.10 ) are rejected. Accordingly, p-values should be below 0.05 and coefficients should be above 0.10 in order to be accepted (Hair et al., 2014). Based upon the aforementioned criteria, two pathways/hypotheses were rejected because of insignificance based upon p-values above the acceptable limits: hypothesis 4 management's intention to supply chain resilience and hypothesis 5 digital infrastructure capability to innovation adoption. Significant pathways should be examined for their contribution to their respective inner model variables; moreover, the greater the pathway coefficient, the greater the impact made upon respective constructs (Hair et al., 2014). Pathway coefficient values correspond to the percent of variance explained by the preceding variable (Hair et al., 2014); therefore, considering that the first pathway (supply chain disruption orientation to innovation adoption) reveals a 0.272 pathway coefficient, it corresponds to $27.2 \%$ of explained variance for innovation adoption being explained by supply chain disruption orientation. Supply chain disruption orientation also positively impacted supply chain resilience (0.397). Management's intention (0.269) positively impacted innovation adoption but not supply chain resilience (it was insignificant and the pathway coefficient was below 0.10). Digital infrastructure capability only significantly impacted supply chain resilience (0.259), not innovation adoption. Innovation adoption positively affected both supply chain resilience (0.225) and operational performance (0.364). Finally, the greatest impact was between supply chain resilience and operational performance (0.550). Pathways can be reviewed in Table 4: Pathway Assessment.

Table 4

Pathway Assessment

\begin{tabular}{|c|c|c|c|c|c|}
\hline Hypotheses & Pathways & $\begin{array}{c}\text { Pathway } \\
\text { Coefficient }\end{array}$ & t-stats & p-value & Results \\
\hline H1 & SC Disruption Orientation $\rightarrow$ Innovation Adoption & 0.272 & 1.989 & 0.024 & Accept \\
\hline $\mathrm{H} 2$ & SC Disruption Orientation $\rightarrow$ SC Resilience & 0.397 & 3.056 & 0.001 & Accept \\
\hline $\mathrm{H} 3$ & Management's Intention $\rightarrow$ Innovation Adoption & 0.269 & 2.490 & 0.007 & Accept \\
\hline $\mathrm{H} 4$ & Management's Intention $\rightarrow$ SC Resilience & 0.063 & 0.726 & 0.234 & Reject \\
\hline H5 & Digital Infrastructure Capability $\rightarrow$ Innovation Adoption & 0.223 & 1.610 & 0.054 & Reject \\
\hline H6 & Digital Infrastructure Capability $\rightarrow$ SC Resilience & 0.259 & 1.769 & 0.039 & Accept \\
\hline $\mathrm{H} 7$ & Innovation Adoption $\rightarrow$ Operational Performance & 0.364 & 4.097 & 0.000 & Accept \\
\hline H8 & Innovation Adoption $\rightarrow$ SC Resilience & 0.225 & 1.842 & 0.033 & Accept \\
\hline H9 & SC Resilience $\rightarrow$ Operational Performance & 0.550 & 5.493 & 0.000 & Accept \\
\hline
\end{tabular}

SC refers to Supply Chain

After examining the pathway coefficients, it is customary to review the coefficient of determination $\left(\mathrm{R}^{2}\right)$ and cross-validated redundancy $\left(\mathrm{Q}^{2}\right)$. The coefficient of determination $\left(\mathrm{R}^{2}\right)$ is a measure of the model's predictive accuracy for the endogenous variables; moreover, values are assessed according to their impacts: substantial (greater than 0.75), moderate (greater than 0.50 but less than 0.75 ) and weak (greater than 0.25 but less than 0.50) (Hair et al., 2011; Henseler et al., 2009). Accordingly, innovation adoption exhibits a weak coefficient of determination while supply chain resilience and operational performance demonstrate moderate predictive accuracy. Even psychosomatic structural equation models with weak predictive accuracy are considered valuable for scholars and practitioners alike. Cross-validated redundancy $\left(\mathrm{Q}^{2}\right)$ is a measure of predictive relevance; moreover, the greater the value, the greater the predictive relevance; ultimately, any value above 0 is considered acceptable. Values for predicative relevance of the following endogenous variables include, 0.245 for innovation adoption, 0.384 for supply chain resilience and 0.396 for operational performance. Values for both the cross-validated redundancy and the coefficient of determination can be reviewed in Table 5: Inner Model Assessment.

Table 5

Structural Model Assessment

\begin{tabular}{ccc}
\hline Endogenous variables & $\mathrm{R}^{2}$ & $\mathrm{Q}^{2}$ \\
\hline Innovation Adoption & 0.375 & 0.245 \\
Supply Chain Resilience & 0.607 & 0.384 \\
Operational Performance & 0.671 & 0.396 \\
\hline
\end{tabular}

Lastly, goodness-of-fit should be measured for any structural equation model. Unfortunately, there remains no standard goodness-of-fit measure for subscribers of PLS-SEM; some argue none should be used as there is no universally agreed upon measure while others argue it is the decision of the researcher to choose a measure (Henseler and Sarstedt, 2013). Two measures have emerged as potential measures of goodness-of-fit measures for PLS-SEM (Sarstedt et al., 2014; Wetzel et al., 2009). For this model we chose the measurement prescribed by Wetzel et al., (2009) because it provides a higher grade of resolution where we can judge the degree of fit as either minor ( 0.1 or above), moderate $(0.25$ or above $)$ or great ( 0.36 or above). According to this measure, the global goodness-of-fit for the model is great (0.5248). Goodness-of-fit can be reviewed in Table 6: Goodness-of-Fit. 
Table 6

Goodness-of-Fit

\begin{tabular}{ccl}
\hline Description & Value & Baseline value \\
\hline Goodness of Fit $(\mathrm{GoF})$ & $\sqrt{\text { Cut }- \text { off of AVE X average of R_square }}=$ & $\begin{array}{l}\text { GoF small }=0.1 \\
\text { GoF medium }=0.25\end{array}$ \\
& $\sqrt{0.5 \mathrm{X} 0.551}=\mathbf{0 . 5 2 4 8}$ & GoF large $=0.36$
\end{tabular}

\subsection{Mediation effects}

Mediation effects can be measured in several ways (Hair et al., 2014; Nitzl et al., 2016; Cepeda et al., 2018; Aghajanian, 2018); moreover, the Sobel test is a common test for mediation. The results of the Sobel mediation tests can be reviewed in Table 7: Mediation Effects of the Sobel Test. Mediation effects were found for five of the seven proposed mediation hypotheses. Supply chain resilience mediated the relationship between supply chain disruption orientation and operational performance. Supply chain resilience also mediates the relationship between digital technology capability and operational performance. Finally, supply chain resilience was also found to mediate the relationship between innovation adoption and operational performance. Innovation adoption was found to mediate the relationship between supply chain disruption orientation and operational performance. Additionally, innovation adoption also mediated the relationship between management's intention and operational performance. Other pathways were tested but not found to be significant. Implications of this research are covered in the following section.

Table 7

Mediation Effects of the Sobel Test

\begin{tabular}{|c|c|c|}
\hline Mediating Pathways: & $\begin{array}{c}\text { Mediation } \\
\text { Effect } \\
\text { (Z-value) }\end{array}$ & P-value \\
\hline H10: SC Disruption Orientation $\rightarrow$ Innovation Adoption $\rightarrow$ Operational Performance & $1.786^{* *}$ & 0.037 \\
\hline H11: SC Disruption Orientation $\rightarrow$ SC Resilience $\rightarrow$ Operational Performance & $2.669 * * *$ & 0.007 \\
\hline H12: Management's Intention $\rightarrow$ Innovation Adoption $\rightarrow$ Operational Performance & $2.127 * *$ & 0.016 \\
\hline H15: Digital Infrastructure Capability $\rightarrow$ SC Resilience $\rightarrow$ Operational Performance & $1.677 * *$ & 0.046 \\
\hline H16: Innovation Adoption $\rightarrow$ SC Resilience $\rightarrow$ Operational Performance & $1.748 * *$ & 0.040 \\
\hline
\end{tabular}

Mediating variables are in bold.

\section{Discussion}

COVID-19 has proven to be a demanding adversary regarding supply chain interruptions (Goodman et al., 2021). Based upon this research model and its findings, South Korean manufacturers have developed improved operational performance through attention to the supply chain and the adoption of pertinent innovations; in particular, they have utilized digital infrastructure capability, supply chain disruption orientation and management's intention to adopt the best innovations for improved supply chain resilience and operational performance. It is likely other manufacturers around the world have done the same; thus, this research is particularly valuable amid the COVID-19 pandemic and other tumultuous supply chains. It highlights key variables for manufacturers interested in developing a competitive advantage amid supply chain dynamism. Manufactures that are able to maintain operations while others are shutting down are able to satisfy current customers and rapidly absorb new customers. The result is a significant competitive advantage over competitor manufacturers. Recalling the soft defences of the Swiss cheese model, organizational culture (supply chain disruption orientation) and management (management's intention), indeed play a vital role in helping a firm to adopt the proper innovations for developing supply chain resilience and operational performance. Management's intention had its greatest impact on the adoption of innovation. As innovation adoption mediates the relationship between management's intention and operational performance, it means appropriate innovations are especially important for developing operational performance. Again, this makes sense, inappropriate innovations will not help supply chain managers to map and visualize the supply chain (Mubarik, et al., 2021); thus, resilience will not be developed unless meaningful innovations are adopted. Managers know which innovations are likely to be most useful; without management's involvement, it is unlikely that meaningful innovations would be adopted. Supply chain disruption orientation did not significantly impact innovation adoption; the organization's culture does not seem to impact the adoption of innovations regarding the supply chain; it seems that the organizational culture is as critical as management with regard to innovation adoption. Supply chain disruption orientation did impact supply chain resilience. Organizational culture does seem to significantly impact an organization's development of supply chain resilience. Supply chain resilience is the collective effort of the entire organization. Without all employees watching out and participating, it is likely difficult to fully visualize the organization's supply chain and be agile enough to adapt to interruptions. Indeed, supply chain disruption orientation is important for supply chain resilience. Innovation adoption and supply chain resilience both mediate the relationships between supply chain disruption orientation and operational performance. The effects of organizational culture are amplified by both innovation adoption and supply chain resilience. Organizational culture is most meaningful for operational performance when it develops concrete improvements for the company. An organizational culture that leads to supply chain resilience is helping the company to be more agile amid supply chain interruptions; thus, the 
company can adapt to interruptions before they affect operations. An organizational culture that is alert and aware of potential supply chain interruptions before they arise will catch them and fix them before they affect operations. Additionally, appropriate innovations should develop supply chain capabilities into the organization, sharpening the capabilities of an organization's culture. Organizations with talented supply chain management and a sharp organizational culture are able to choose appropriate innovations and develop supply chain resilience. Hard defences in the Swiss cheese model including digital infrastructure capability, also play a critical role in improving supply chain resilience and operational performance. Digital infrastructure capability did not have a significant impact on the adoption of innovation; in other words, having technology does not make it more likely new innovations will be adopted. New innovations do not always equate to a better means of mapping and visualizing supply chains; current technology is likely comfortable to use and already meaningful. Nevertheless, digital infrastructure capability does help a firm to develop supply chain resilience. Supply chain mapping and visualization are facilitated by digital technology (Mubarik et al., 2021); without digital technology today, it would be impossible to visualize the supply chain and adapt to interruptions as they occur; thus sparing the organization from operational shutdowns and increased costs. The relationship between digital infrastructure capability and operational performance is mediated by supply chain resilience; therefore, when digital infrastructure capability leads to supply chain resilience, it is more meaningful for operational performance. Companies should make sure they utilize digital infrastructure in order to visualize the supply chain so that interruptions can be dealt with in a timely manner to avoid operational problems. Digital technology is key to visualization and problem mitigation. Supply chain resilience also mediates the relationship between innovation adoption and operational performance. In this regard it seems innovations that help a firm to develop supply chain resilience are most meaningful for operational performance. Companies should invest in innovations that develop supply chain resilience especially amid tumultuous supply chains.

The strong impact of innovation adoption upon supply chain resilience and the impact of digital infrastructure capability may also imply a double loop learning capability. Firms adopt innovations in processes and operations; it is likely that those innovations, as noted previously, are associated with the type of double loop learning described by Argyris and Schön (1974); accordingly, manufacturers are able to avoid disruptions they had previously encountered through a double looped learning process. It seems especially logical for firms to search out opportunities to exploit double loop learning amid a tumultuous supply chains. Supply chain disruption orientation, management's intention and digital infrastructure capability facilitate the double loop learning which helps to develop supply chain resilience and operational performance.

\section{Conclusion}

\subsection{Contributions}

Several contributions should be noted for practitioners and scholars. The theoretical framing of this model, the resourcebased view, suggests that practitioners are ultimately striving to organize resources in order to develop resilience and performance; thus, establishing competitive advantages. Utilizing a plethora of theory, a new model is presented and proven through this study. Fundamentally, normal accident theory and the Swiss cheese model are used to understand how environmental stimuli and internal processes create interruptions and how a firm can intervene to develop resilience amid disruption. Organizational learning substantiates the importance of organizations investing in technological infrastructure; practitioners should continuously invest in the latest technologies especially if they hope to build up resilience and performance. Organizational culture should not be neglected; all employees are tasked with staying alert and visualizing the supply chain. Organizational culture also sways the decisions of management. Building a culture that encourages alertness and adaptability can improve resilience and performance. Several theories were amalgamated to understand management intention and innovation adoption including, TOE, DOI, TAM, UTAUT, and TPB underscoring the complexity of this particular area of study. Ultimately, organizational information processing theory coalesces much to reveal an organization's integration of information absorption and its utilization; firms use information to adapt, adopt appropriate technology and use it appropriately to build resilience and performance. The rapid and proper processing of information guides a company to the best decisions regarding technology; moreover, experienced managers seem to be critical. Practitioners hoping to engender supply chain resilience and operational performance should approach this endeavor holistically by investing in supply chain technological infrastructure, building managerial expertise, and developing an organizational culture that is conducive to such change.

This research contributes to several areas of study regarding supply chain management: disruption/interruption management, process innovation, innovation adoption, supply chain resilience, operational performance, and supply chain disruption orientation. Scholars and practitioners mandate evidence-based studies that guide them through the supply chain tumult of COVID-19; this research suffices. Supply chain managers and practitioners can embrace technology (digital infrastructure capability), experienced management and organizational culture (supply chain disruption orientation) to adopt pertinent innovations, produce supply chain resilience and improve operational performance. The internalization of innovation into improved operations indicates that innovation is not always outwardly noticed; many times the most relevant innovations are happening inside the company as process innovations. This study also highlights the importance of internal operational performance for gaining rapid competitive advantages during acute crises. 


\subsection{Limitations and future studies}

There are limitations to this study. This research sample is limited to South Korean manufacturers that may exhibit more or less dynamo than other manufacturers globally. It may not be possible to generalize these results without further studies. Indeed, additional research on manufacturers of different nations may have divergent performance. Future studies could focus on comparing the behavior of other firms globally. As supply chain issues tend to be important for many types of companies, it may be relevant to test these results against firms of other sectors including services. Comparative studies could elucidate idiosyncrasies in how technology and innovations are adopted by various firms and their resultant impacts upon supply chain resilience and operational performance. As the tumult of COVID-19 subsides, it seems relevant to question whether the supply chain resilience gained during the acute crisis is still valuable afterwards. It is possible that innovation adoption here has moved the firm to innovate in other areas. Perhaps the firm has gained operational excellence in other unforeseen places. It seems that research post-COVID-19 could reveal much with regard to how innovative companies have survived but also how they will continue into the future.

\section{References}

Aghajanian, S. (2018). An Empirical Procurement Risk Management Framework in Supply Chain Networks: A Hybrid Approach. Industrial Engineering and Management Systems, 17(4), 730-744.

Akman, I. \& Mishra, A. (2014). Green information technology practices among IT professionals: Theory of planned behavior perspective. Problems of Sustainable Development, 9(2), 47-54.

Ali, A., Mahfouz, A., \& Arisha, A. (2017). Analysing supply chain resilience: integrating the constructs in a concept mapping framework via a systematic literature review. Supply Chain Management, 22(1), 16-39.

Ali, I. \& Shukran, K. (2016). Managing supply chain risks and vulnerability through collaboration: Present and future scope. The Journal of Developing Areas, 50(5), 335-342.

Ali, M., Suleiman, N., Khalid, N., Tan, K., Tseng, M., \& Kumar, M. (2021). Supply chain resilience reactive strategies for food SMEs in coping to COVID-19 crisis. Trends in Food Science \& Technology, 109, 94-102.

Ambulkar, S., Blackhurst, J., \& Grawe, S. (2015). Firm's resilience to supply chain disruptions: Scale development and empirical examination. Journal of Operations Management, 33, 111-122.

Argyris, C. \& Schön, D. A. (1974). Theory in practice: Increasing professional effectiveness. Jossey-Bass.

Asadi, S., Nilashi, M., Safaei, M., Abdullah, R., Saeed, F., Yadegaridehkordi, E., \& Samad, S. (2019). Investigating factors influencing decision-makers' intention to adopt Green IT in Malaysian manufacturing Industry. Resources, Conservation and Recycling, 148, 36-54.

Barclay, M. J., Smith, C. W., \& Watts, R. L. (1995). The determinants of corporate leverage and dividend Policies. Journal of Applied Corporate Finance, 7(4), 4-19.

Barney, J. (1991). Firm resources and sustained competitive advantage. Journal of Management, 17(1), 3-15.

Baz, J. \& Ruel, S. (2021). Can supply chain risk management practices mitigate the disruption impacts on supply chains' resilience and robustness? Evidence from an empirical survey in a COVID-19 outbreak era. International Journal of Production Economics, 233, 107972.

Belhadi, A., Kamble, S., Jabbour, C. Gunasekaran, A., Ndubisi, N., \& Venkatesh, M. (2021). Manufacturing and service supply chain resilience to the COVID-19 outbreak: Lessons learned from the automobile and airline industries. Technological Forecasting \& Social Change, 163, 120447.

Blackhurst, J., Dunn, K. S., \& Craighead, C. W. (2011). An empirically derived framework of global supply Resiliency. Journal of Business Logistics, 32(4), 374-391.

Blome, C., Schoenherr, T., \& Rexhausen, D. (2013). Antecedents and enablers of supply Chain agility and its effect on performance: a dynamic capabilities perspective. International Journal of Production Research, 51(4), $1295-1318$.

Bode, C., Wagner, S. M., Petersen, K. J., \& Ellram, L. M. (2011). Understanding responses to supply chain disruptions: Insights from information processing and resource dependence perspectives. Academy of Management Journal, 54(4), 833-856.

Bret, A. J. (2020). COVID-19 Response and Recovery: Some views from UNCITRAL. International Trade Law, 148(3), 315.

Brusset, X. \& Teller, C. (2017). Supply chain capabilities, risks, and resilience. International Journal of Production Economics, 184, 59-68.

Cepeda-Carrion., G., Juan, -G. C. -N., \& Cillo, V. (2018). Tips to use partial least squares structural equation modelling (PLS-SEM) in knowledge management. Journal of Knowledge Management, 23(1), 67-89.

Chandra, C. \& Grabis, J. (2007). Supply Chain Configuration: concepts, solutions, and applications. Springer.

Chen, Y., Duan, L., \& Zhang, W. (2020). Effect of User Involvement in Supply Chain Cloud Innovation: A Game Theoretical Model and Analysis. Journal of Global Information Management, 28(1), 23-38.

Chen, Y., Tang, G., Jin, J., Li, J., \& Paillé, P. (2015). Linking market orientation and environmental performance: The influence of environmental strategy, employee's environmental involvement, and environmental product quality. Journal of Business Ethics, 127(2), 479-500.

Chopra, S. \& Meindl, P. (2010). Supply Chain Management: Strategy, Planning, and Operation, Pearson Education. 
Chowdhury, M., Quaddus, M., \& Agaarwal, R. (2019). Supply chain resilience for performance: role of relational practices and network complexities. Supply Chain Management: An International Journal, 24(5), 659-676.

Cooper, M. C., Lambert, D. M., \& Pagh, J. D. (1997). Supply chain management: More than a new name for Logistics. The International Journal of Logistics Management, 8(1), 1-14.

Davis, F. D. (1989). Perceived usefulness, perceived ease of use and user acceptance of information Technology. MIS Quarterly, 13(3), 319-339.

DiMaggio, P. J. \& Powell, W. W. (1983). And collective rationality in organizational fields. American Sociological Review, 48(2). 147-160.

European Journal of Operational Research, 247, 1-15.

Flynn, B., Huo, B., \& Zhao, X. (2010). The impact of supply chain integration on performance: A contingency and configuration approach. Journal of Operations Management, 28, 58-71.

Fornell, C. \& Larcker, D. F. (1981). Structural equation models with unobservable variables and Measurement error: Algebra and Statistics. Journal of Marketing Research, 18(3), 382-388.

Galbraith, J. R. (1974). Organization Design: An Information Processing View. Interfaces, 4(5), $28-36$.

Galbraith, J. R. (1973). Designing Complex Organizations. Addison-Wesley. MA. USA.

Golgeci, I. \& Y. Ponomarov, S. (2013). Does firm innovativeness enable effective responses to supply chain disruptions? An empirical study. Supply Chain Management, 18(6), 604-617.

Goodman, P. S., Stephenson, A., Chokshi, N., \& Corkery. M. (2021). I've Never Seen Anything Like This': Chaos Strikes Global Shipping. The New York Times. Retrieved March 15.2021 : https://www.nytimes.com/2021/03/06/business/global-shipping.html

Gu, M. \& Huo, B. (2021). The impact of information technology usage on supply chain resilience and performance: an ambidextrous view. International Journal of Production Economics, 232, 107956.

Gu, M. \& Huo, B. (2017). The impact of supply chain resilience on company performance: a dynamic capability perspective. Academy of Management Proceedings, 2017(1).

Han, H. \& Hyun, S. S. (2017). Impact of hotel-restaurant image and quality of physical-environment, service, and food on satisfaction and intention. International Journal of Hospitality Management, 63, 82-92.

Henseler, J., Ringle, C. M., \& Sinkovics, R. R. (2009). The use of partial least squares path modeling in international marketing. In New challenges to international marketing. Emerald Group Publishing Limited.

Henseler, J., \& Sarstedt, M. (2013). Goodness-of-fit indices for partial least squares path modeling. Computational Statistics, 28(2), 565-580.

Hair. Jr., J. Hult, G., Ringle, C., \& Sarstedt, M. (2014). A primer on Partial Least Squares Structural Equation Modeling $P L S-S E M$. Sage publications Ltd.

Hosseinian, S. S. \& Zahra, J.J. (2012). Major theories of construction accident causation models: A literature review. International Journal of Advances in Engineering and Technology, 4(2), 55-66.

Jee, J. \& Bae, E. (2020). 감염병 확산 모형을 이용한 경제전망. Bank of Korea, 74(6), 16-38.

Jermsittiparsert, K., Sutduean, J., \& Sriyakul, T. (2019). Effect of Service Innovation and Market Intelligence on Supply Chain Performance in Indonesian Fishing Industry. Industrial Engineering and Management Systems 18(3), $407-416$.

Jihadi, M., Usman, I., Asrini, A. Musnaini, M. Lutfi, L., Indrawijaya, S., \& Dahmiri, D. (2020). The Effect of Supply Chain Dynamism and Supply Chain Disruption Orientation on Supply Chain Resilience in Indonesian Manufacturing Industry. International Journal of Supply Chain Management, 9(4), 2051-3771.

Jüttner, U., Peck, H., \& Martin, C. (2003). Supply chain risk management: outlining an agenda for future research. International Journal of Logistics: Research and Application, 6(4), 197-210.

Jüttner, U. \& Maklan, S. (2011). Supply chain resilience in the global financial crisis: an empirical study. Supply Chain Management: An International Journal, 16(4), 246-259.

Kamalahmadi, M. \& Mellat-Parast, M. (2016). Developing a resilient supply chain through Supplier flexibility and reliability assessment. International Journal of Production Research, 54(1), 302-321.

Kang, M. \& Kim, S. (2017). A Study of the Effects of Relational Characteristics as an Antecedent to SCM Activity and Performance among Taiwanese Manufacturing Companies. International Business Review, 21(4), 167-191.

Kaplan, R. S. \& Norton, D. P. (1996). Using the balanced scorecard as a strategic management system. Harvard Business Review, 35-47.

Liu, S., Zhang, J., Keil, M., \& Chen, T. (2010). Comparing senior executive and project manager perceptions of IT project risk: a Chinese Delphi study. Information Systems Journal, 20(4), 319-355.

Nitzl, C., Roldan, J.L., \& Cepeda, G. (2016). Mediation analysis in partial least squares path modeling: Helping researchers discuss more sophisticated models. Industrial Management and Data Systems, 116(9), 1849-1864.

Nunnally, J. C. \& Bernstein, I. H. (1994). Psychometric theory, 3rd. New York. NY: McGraw-Hill.

Manners-Bell, J. (2020). Supply Chain Risk Management: How to design and manage resilient supply Chains. 3rd edition. Kogan Page.

Marcoulides, G. A. \& Saunders, C. (2006). Editor's comments: PLS: a silver bullet? MIS Quarterly, 30(2). 3-4.

Mentzer, J., DeWitt, W., Keebler, J., Min, S., Nix, N., Smith, C., \& Zacharia, Z. (2001). Defining supply chain Management. Journal of Business Logistics, 22(2), 1-25.

Melnyk, S. A., Closs, D. J., Griffs, S.E., Zobel, C. W., \& Macdonal, J. R. (2014). Understanding supply chain Resilience. Supply Chain Management Review, 18(1), 34-41. 
Mubarik, M., Naghavi, N., Mubarik, M., Kusi-Sarpong, S., Khan, S., Zaman, S., \& Kazmi, S. (2021). Resilience and cleaner production in industry 4.0: Role of supply chain mapping and visibility. Journal of Cleaner Production, $292,1-12$.

Ocasio, W. (1997). Towards an attention-based view of the firm, Strategic Management Journal, 18 (1), $187-206$.

Parast, M. M. (2020). The impact of R\&D investment on mitigating supply chain disruptions: Empirical evidence from US firms. International Journal of Production Economics, 227, 107671.

Perrow, C. (1994). Accidents in high-risk systems. Technology Studies, 1(1), 1-20.

Pike, J., Bogich, T., Elwood, S., Finnoff, D., \& Daszak, P. (2014). Economic optimization of a global strategy to address the pandemic threat. Proceedings of the National Academy of Sciences of the United States of America, 111(52), 1851918523.

Polyviou, M., Croxton, K., \& Knemeyer, A. (2020). Resilience of medium-sized firms to supply chain disruptions: the role of internal social capital. International Journal of Operations and Production Management, 40(1), 68-91.

Ponis, S. (2010). Managing Risk in Virtual Enterprise Networks: Implementing Supply Chain Principles. Business Science Reference, 2010, 184-304.

Puviyarasu, S.A., \& Cunha, C. (2021). Smart Factory: From concepts to operational sustainable outcomes using test-beds. Log Forum, 17(1), 7-23.

Qazi, A., Dickson, A., Qingley, J., \& Gaudenzi, B. (2018). Supply chain risk network management: A Bayesian belief network and expected utility-based approach for managing supply chain risks. International Journal of Production Economics, 196, 24-42.

Reason, J. T. (1977). Skill and error in everyday life. In M. J. A. Howe (Ed.). Adult learning. London: Wiley.

Richter, N. F., Cepeda-Carrion, G., Roldán Salgueiro, J. L., \& Ringle, C. M. (2016). European management research using partial least squares structural equation modeling PLS-SEM. European Management Journal, 34(6), 589-597.

Ringle, C. M., Sarstedt, M., \& Straub, D. W. (2012). Editor's comments: a critical look at the use of PLS-SEM in "MIS Quarterly". MIS Quarterly, 36(1), 1-12.

Rogers, E. M. (2003). Diffusion of Innovations. 5th ed. New York: Free Press.

Sagan, S. D. (1995). The limits of safety: Organizations, Accidents, and Nuclear Weapons. Princeton University Press.

Sawik, T. (2020). Supply Chain Disruption Management: Using Stochastic Mixed Integer Programming. 2nd Edition. Springer.

Sarstedt, M., Ringle, C. M., Smith, D., Reams, R., \& Hair Jr, J. F. (2014). Partial least squares structural equation modeling PLS-SEM: A useful tool for family business researchers. Journal of Family Business Strategy, 5(1), $105-115$.

Scheer, A.W., Kruppe, H., Jost, W., \& Kindermann, H. (2006). Agility by ARIS Business Process Management. Springer.

Scholten, K. \& Schilder, S. (2015). The role of collaboration in supply chain resilience. Supply Chain Management: An International Journal, 20(4), 471-484.

Sheffi, Y. (2005). The Resilient Enterprise. Massachusetts Institute of Technology.

Sheffi, Y. \& Rice, Jr. J. B. (2005). A supply chain view of the resilient enterprise. Sloan Management Review, 47(1), 41-48.

Simões, A., Soares, A., \& Barros, A. (2020). Factors influencing the intention of managers to adopt collaborative robots(cobots) in manufacturing organizations, Journal of Engineering and Technology Management, 57, 1-15.

Singh, N. S. \& Singh, S. (2019). Building supply chain risk resilience: Role of big data analytics in supply chain disruption mitigation. Benchmarking: An International Journal, 26(7), 2318-2342.

Stead, E. \& Smallman, C. (1999). Understanding business failure: learning and un-learning from industrial crises, Journal of Contingencies and Crisis Management, 7(1), 1-18.

Stevenson, M. \& Busby, J. (2015). An exploratory analysis of counterfeiting strategies. International Journal of Operations and Production Management, 35(1), 110-144.

Tashanova, D., Sekerbay, A., Chen, D., Luo, Y., Zhao, S., \& Zhang, Q. (2020). Investment Opportunities and Strategies in an Era of Coronavirus Pandemic. Doi: https://ssrn.com/abstract=3567445http://dx.doi.org/10.2139/ssrn.3567445.

Tornatzky, L.G. \& Fleischer, M. (1990). The Process of Technology Innovation. Lexington: Lexington Books.

Vagnani, G. \& Vlope, L. (2017). Innovation attributes and managers' decisions about the adoption of innovations in organization: A meta-analytical review. International Journal of Innovation Studies, 1, 107-133.

Venkatesh, V., Morris, M., Davis, G., \& Davis, F. (2003). User Acceptance of Information Technology: Toward a Unified View. MIS Quarterly, 27, 425-478.

Wagner, S. \& Bode, C. (2008). An Empirical Examination of Supply Chain Performance Along Several Dimension of Risk. Journal of Business Logistics, 29, 307-325.

Wetzels, M., Odekerken-Schröder, G., \& Oppen, C. (2009). Using PLS path Modeling for Assessing Hierarchical Construct Models: Guidelines and Empirical Illustration. MIS Quarterly, 33(1), 177-195.

Wong, C. W., Lirn, T. C., Yang, C. C., \& Shang, K. C. (2020). Supply chain and external conditions under which supply chain resilience pays: An organizational information processing theorization. International Journal of Production Economics, 226, 107610.

Yu, W., Jacobs, M. A., Chavez, R., \& Yang, J. (2019). Dynamism, disruption orientation, and resilience in the supply chain and the impacts on financial performance: a dynamic capabilities perspective. International Journal of Production Economics, 218, 352-362. 
(C) 2022 by the authors; licensee Growing Science, Canada. This is an open access article distributed under the terms and conditions of the Creative Commons Attribution (CC-BY) license (http://creativecommons.org/licenses/by/4.0/). 